Editorial

\title{
Application of practice guidelines in underdeveloped countries: does "copy and paste" strategy helps?
}

\section{Editorial}

It is a common scenario, in my country, to see a patient with kidney stones asking for the cheapest single procedure that will render him/ her stone free. As medical practitioners in less developed country with severe economic deficiency and long term instability and poor health system, where there is no medical insurance and all the medical expense falls on the shoulders of the patient, we have to consider the real local situation before ordering an investigation or providing treatment according to what we learnt from text books or international practice guidelines. According to the Global Forum for Health Research less than $10 \%$ of the global spending in health research is devoted to diseases or conditions that account for $90 \%$ of the global disease burden. ${ }^{1}$ Most of the world leading scientific health research and development is performed by scientists and researchers from well developed countries with financial and organizational facilities making a suitable environment of conducting and implementing research activities.

On other hand most of the underdeveloped countries has severe shortage of resources and suffer long term political instability making scientific research an "unobtainable luxury". Most of the so-called "third world" medical schools curricula are based on western made scientific resources that teach and practice medicine suitable for western communities, the application of such practice to the real world of those deprived communities is not always practical. There is no magic solution for the complicated health problems in those deprived communities, but with combined efforts by both local and international societies, significant improvement in medical practice could be achieved. Scientists should struggle to persuade politicians and policy makers on the importance of spending more on the health research and health reform rather than purchasing more weapons. Funding organizations should also focus in giving part of their fund to the research and researchers in those countries with limited research financing.

Local medical societies should make their own practice guidelines, based on both best scientific evidence and local needs and making them applicable to their communities. Finally many innovations can be made to develop tricks that reduce the cost of surgical procedures and produce cheap and effective medical supplies and instruments with very much less cost than those purchased from expensive brands. ${ }^{2,3}$
Volume 5 Issue 2 - 2017

Mohammed Babakri

Faculty of Medicine, Aden University, Yemen

Correspondence: Mohammed Babakri, Faculty of Medicine, Aden University, PO Box 6038 khormaksar Aden, Yemen, Tel 00 967 777401971, Email drbabakri@gmail.com

Received: July 30, 2017 | Published: July 31, 2017

Simply copy and paste management instructions and guidelines from developed to underdeveloped countries without considering the economic, cultural and social differences, is doomed to failure.

\section{Acknowledgments}

I would like to express my great thanks to Professor Gamal M Abdullah, Professor of English from Faculty of Languages, Aden University for his help in grammatical revision of this manuscript.

\section{Conflicts of Interset}

None.

\section{References}

1. Global Forum for Health Research. 10/90 Report on Health Research 1999. World Health Organization, Geneva, Switzerland. 1999.

2. Harris E. Building scientific capacity in developing countries. EMBO Rep. 2004;5(1):7-11.

3. Lezrek M, Tazi H, Slimani A, et al. A Cheaper Simulator for Learning Percutaneous Renal Access: A Latex Glove Model. Journal of Endourology Part B. Videourology. 2004;27(5). 